Article

\title{
On the Spectra of Gravity Waves Generated by Two Typical Convective Systems
}

\author{
Yuan Wang ${ }^{1}$, Lifeng Zhang ${ }^{1, *} \mathbb{0}$, Jun Peng ${ }^{1, *}$, Yun Zhang ${ }^{1}$ and Tongfeng Wei ${ }^{2}$ \\ 1 College of Meteorology and Oceanography, National University of Defense Technology, \\ Nanjing 211101, China \\ 2 Meteorology and Space Weather Monitoring and Warning Center, China Xi' an Satellite Control Center, \\ Xi'an 710000, China \\ * Correspondence: zhanglif_qxxy@aliyun.com (L.Z.); pengjun@nudt.edu.cn (J.P.)
}

Received: 16 June 2019; Accepted: 14 July 2019; Published: 17 July 2019

\begin{abstract}
Spectral characteristics of lower-stratospheric gravity waves generated in idealized mei-yu front and tropical cyclone (TC) are compared by performing high-resolution simulations. The results suggest that the systems which organize convection in different forms can generate waves with distinctly different presentation. The mei-yu front appears as a linear zonal wave source and gravity waves are dominated by cross-frontal (meridional) propagating components. The northward (southward) components have dominant meridional wavelengths of $125-333 \mathrm{~km}(>250 \mathrm{~km})$, periods of 100-200 min (83-143 min), and phase speeds of 0-15 $\mathrm{m} \mathrm{s}^{-1}\left(15-20 \mathrm{~m} \mathrm{~s}^{-1}\right)$. The TC appears as a point wave source and gravity waves propagate equally in various horizontal directions. The waves exhibit greater power and broader spectral distributions compared with those in the mei-yu front, with dominant horizontal wavelengths longer than $62.5 \mathrm{~km}$, periods of 33-600 min, and phase speeds slower than $\sim 40 \mathrm{~m} \mathrm{~s}^{-1}$.
\end{abstract}

Keywords: gravity waves; convective systems; spectral analysis

\section{Introduction}

Gravity-wave activity is a ubiquitous buoyancy oscillation phenomenon in the atmosphere. It has been a fundamental topic within meteorological research due to its profound effect on atmospheric processes at various spatiotemporal scales [1-3]. For example, it can generate and modulate turbulence [4], initiate and organize convection [5], and transfer energy and momentum between different heights [6].

Common sources that initiate gravity waves in the atmosphere include, but are not limited to, topography, convection, wind shear, jet-front systems, and wave-wave interactions [7,8]. Of these, moist convection is considered one of the most important sources of non-stationary gravity waves $[9,10]$. However, convection-induced waves are still not well understood. For example, the generation mechanism of convective gravity waves remains controversial [11-13]. In addition, the spectra of convective gravity waves distribute in a complicated way over a broad range, which are still under-explored [14,15].

As vigorous and well-organized convective systems, both the mei-yu front and tropical cyclone (TC) have important influence on the East Asian monsoon region. Clear signals of gravity waves generated by TCs have been identified by numerous observations [16-19] and simulated successfully using mesoscale models [20-24]. These studies showed that the TC-generated waves have wide spatiotemporal scales, with horizontal wavelengths of $10-2000 \mathrm{~km}$ and periods of $10 \mathrm{~min}-2.5$ days. In contrast, there has been little research into gravity waves generated by the mei-yu front [25-27]. Appearing as a warm-season quasi-stationary frontal zone extending from Eastern China to Japan, the 
mei-yu front contains lots of convective cells, which successively form along the front and gradually organize into quasi-two-dimensional (2D) precipitation bandings, and thus tends to cause persistent precipitation [28-30]. It differs from the common midlatitude front by a weak temperature gradient but a strong moisture gradient, and the frontal zone is characterized by intense equivalent potential temperature gradient [31,32]. Sun [25] analyzed the mesoscale- $\beta$-scale gravity-wave activity during a mei-yu front heavy rain process using surface observation data. She identified the waves with wavelength of $200 \mathrm{~km}$, amplitude of $2 \mathrm{hPa}$, and periods of 6-8 h. Hu [27] discussed the generation, propagation, and dispersion of gravity waves in the mei-yu front based on a linear model with a simple parameterized cumulus heating expression. Based on an idealized model constructed by Peng et al. [33], Wang et al. [34] recently performed high-resolution simulations to investigate the generation mechanism of gravity waves in the mei-yu front system. A mechanical oscillator mechanism was suggested as playing a dominant role in the generation of lower-stratospheric waves.

Due to relatively coarse spatiotemporal resolution, most general circulation models (GCMs) have still been unable to resolve short-scale and high-frequency gravity waves precisely. Consequently, representing the effects of gravity waves in GCMs requires parameterization [35]. However, because of the complexity of convection-induced gravity waves, the relevant parameterization remains under development [36-40]. It has been a consensus that a comprehensive knowledge of convective waves is the premise of making a breakthrough in parameterization. Under this background, understanding convective gravity waves and their convective sources is not only a theoretical interest in wave dynamics but also essential to the improvement of gravity-wave parameterization in GCMs. This is because previous studies showed that the lack of an accurate understanding of convective sources limits the potential calibration of gravity-wave parameterizations with the growing number of observations, and might be a cause of systematic errors [41].

Although they are both significant sources of gravity waves, the mei-yu front and TC display considerably different structures; the former is a quasi-2D linear system, whereas the latter is a vortex-like system. This significant difference of wave-source structure provides us a good opportunity to explore the relation between wave sources and the generated waves by comparison study. What are the spectral features of gravity waves in these two systems? Do prominent spectral differences exist between them? In this paper, the spectra of gravity waves generated by the mei-yu front and TC are investigated and compared using idealized numerical simulations.

\section{Experimental Design}

The numerical model used in this study is the Advanced Research version of the Weather Research and Forecasting (ARW-WRF) model [42].

In the simulation of the mei-yu front, the domain size is $1000 \mathrm{~km} \times 2000 \mathrm{~km}$ and the boundary condition is periodic in the $x$ direction and open in the $y$ direction. An initial front is first constructed in the $y-z$ plane and then expanded to three-dimensional space by assuming zonal homogeneity; thus the front is oriented in the $x$ direction. Environmental moisture and temperature are based on a real sounding during a typical mei-yu period. Further details of the model design can be found in Peng et al. [33]. The Morrison scheme is used for microphysics parameterization [43], and no planetary boundary layer scheme is used.

The TC is simulated in a $2000 \mathrm{~km} \times 2000 \mathrm{~km}$ domain with double periodic boundary conditions. An initial axisymmetric vortex in hydrostatic and gradient-wind balance, with maximum tangential surface wind speed of $15 \mathrm{~m} \mathrm{~s}^{-1}$ at a radius of $135 \mathrm{~km}$, is centered in the model domain. The Jordan [44] mean hurricane season sounding is used for the environmental moisture and temperature profile, and no environmental mean flow exists. The sea surface temperature is fixed at $29^{\circ} \mathrm{C}$. The simulation uses the Yonsei University (YSU) boundary layer scheme [45] with the surface layer scheme of Dudhia et al. [46], and WRF single-moment six-class (WSM6) microphysics [47].

Both simulations are performed on the $f$ plane with 5-km horizontal grid spacing, and the Coriolis parameter $f$ is set to $1.0 \times 10^{-4}$ and $5.0 \times 10^{-5} \mathrm{~s}^{-1}$ for the mei-yu front and TC simulations, respectively. 
Note that according to the results of sensitivity experiments (not shown), the difference of microphysics parameterization and Coriolis parameter between these two simulations does not affect the results and conclusions in this study. The model has 61 vertical levels, with the top at $30 \mathrm{~km}$ and Rayleigh damping applied to the vertical velocity in the upper $5 \mathrm{~km}$ of the model domain to prevent artificial reflection of gravity waves from the model top [48]. Nested domains are not adopted to avoid the possibility of spurious reflection and distortion of waves from the lateral boundaries [49]. For simplicity, both topography and radiation are ignored.

\section{Results}

\subsection{Overview of the Simulations}

Mass-weighted average vertical kinetic energy, defined as VKE $=\iiint \frac{1}{2} \rho w^{2} d x d y d z / \iiint \rho d x d y d z$, is calculated to describe the evolution of the simulated mei-yu front system (Figure 1a), where $\rho$ and $w$ are density and vertical wind, respectively. The integration of the front is performed for $z=0-15 \mathrm{~km}$ over the entire horizontal domain. As seen in previous studies of the idealized mei-yu front [33], no convection occurs during the initial adjustment of the front. During the intensification phase $(t=15-25 \mathrm{~h})$, the moist convection bursts at $15 \mathrm{~h}$ and reaches its peak at $16 \mathrm{~h}$, with a maximum vertical kinetic energy of $0.044 \mathrm{~m}^{2} \mathrm{~s}^{-2}$. The convection then gradually weakens and maintains a steady intensity in the mature phase $(t=26-36 \mathrm{~h})$, during which the typical mei-yu frontal structure is established (not shown). The 1-h accumulated precipitation at $26 \mathrm{~h}$ exhibits a classical meso- $\alpha$-scale rainband of the mei-yu front, with several embedded rain clusters (Figure 1b).
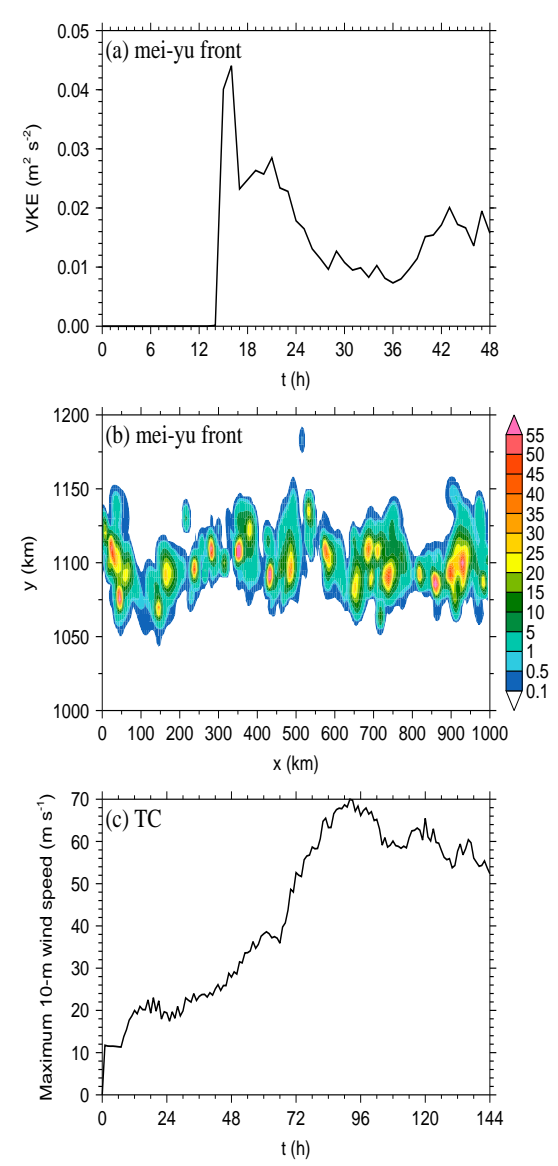

Figure 1. Simulated (a) times series of mass-weighted average vertical kinetic energy and (b) 1-h accumulated precipitation at $t=26 \mathrm{~h}$ (shaded; $\mathrm{mm}$ ) for the mei-yu front. (c) Simulated time series of maximum 10-m wind speed for the tropical cyclone (TC). 
The time series of 10-m maximum wind speed of the simulated TC is shown in Figure 1c. The wind speed increases notably from $\sim 24 \mathrm{~h}$, implying the intensification of the TC. The maximum intensity occurs at $92 \mathrm{~h}$, with a 10-m maximum wind speed of $\sim 70 \mathrm{~m} \mathrm{~s}^{-1}$ as the TC reaches maturity.

Figure 2 shows the horizontal and vertical cross sections of vertical velocity and potential temperature at selected times for the simulated mei-yu front and TC. For the mei-yu front at $26 \mathrm{~h}$, the strongest convection is located along $y=\sim 1100 \mathrm{~km}$ (Figure 1b). Prominent gravity-wave signals appear in the lower stratosphere at $17 \mathrm{~km}$, well above the convection (Figure 2a). For the TC at $104 \mathrm{~h}$, the lower-stratospheric waves exhibit a circular concentric distribution, radiating outwards from the storm center (Figure 2b). In the vertical cross sections, the waves generated in both systems show the typical pattern of convective gravity waves. Upright convection in the troposphere induces waves propagating upward into the lower stratosphere, and propagating outward both upstream and downstream (Figure 2c,d).
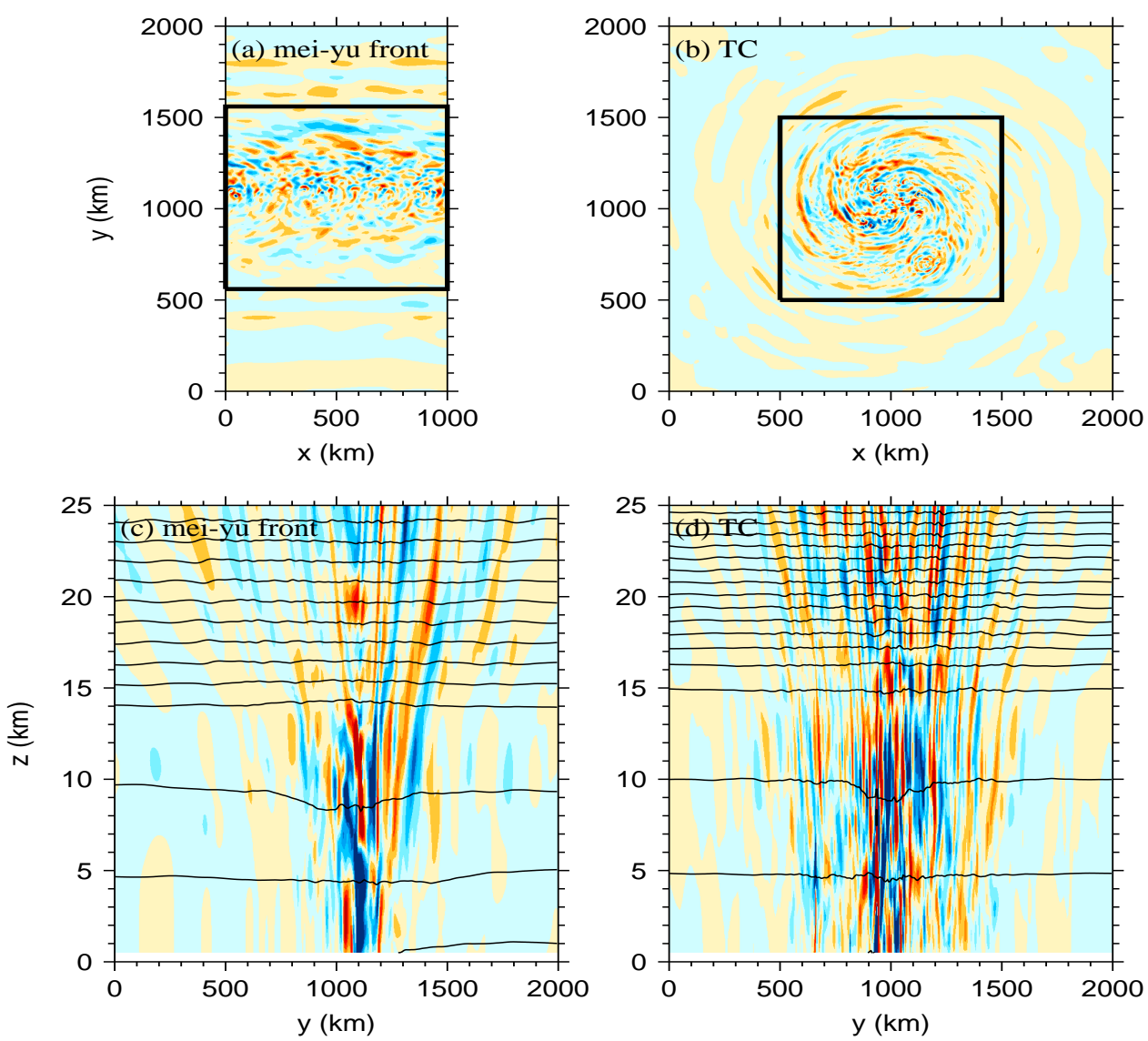

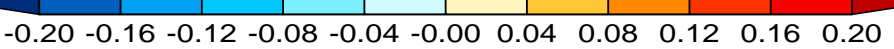

Figure 2. Simulated $(\mathbf{a}, \mathbf{b})$ horizontal cross sections of vertical velocity (shaded; $\mathrm{m} \mathrm{s}^{-1}$ ) at $z=17 \mathrm{~km},(\mathbf{c}, \mathbf{d})$ vertical cross sections of vertical velocity (shaded; $\mathrm{m} \mathrm{s}^{-1}$ ) and potential temperature (contours every $20 \mathrm{~K}$ ) along (c) $x=500 \mathrm{~km}$ and (d) $x=1000 \mathrm{~km}$. The left panels are for the mei-yu front at $t=26 \mathrm{~h}$ and the right panels are for the TC at $t=104 \mathrm{~h}$. Boxes in the top panels indicate the wave analysis domains.

\subsection{Spectral Analysis of the Lower-Stratospheric Gravity Waves}

In this section, the spectral characteristics of the lower-stratospheric gravity waves during the mature phase of the mei-yu front and TC are investigated in detail using data with a time interval of $5 \mathrm{~min}$. The TC has a longer life cycle than the mei-yu front. However, to facilitate the comparison of gravity waves in these two systems, we define the mature phase of the simulated TC, which is comparable in length of time with that of the mei-yu front, as $t=104-114 \mathrm{~h}$ according to the 
minimum 10-h standard deviation of the 10-m maximum wind speed. For exactly the same reason, a $1000 \mathrm{~km} \times 1000 \mathrm{~km}$ horizontal domain is used to perform wave analysis for both systems. According to the position of the rainband, the wave analysis domain for the mei-yu front is determined as $0<x<1000 \mathrm{~km}, 560<y<1560 \mathrm{~km}$ (Figure 2a), such that the quasi-zonal strong updraft approximately coincides with the zonal central axis of the analysis domain. Due to the absence of environmental flow, the TC moves little, with its center almost always located at $(x, y)=(1000,1000) \mathrm{km}$. The wave analysis domain for the TC is therefore $500<x<1500 \mathrm{~km}, 500<y<1500 \mathrm{~km}$ (Figure 2b). For convenience, we hereafter denote the wave analysis domain as $-500<x<500 \mathrm{~km},-500<y<500 \mathrm{~km}$.

Gravity wave perturbations are calculated as in Kim et al. [20]. The components that satisfy the vertical propagation condition of inertia-gravity waves $(f<\hat{\omega}<N)$ are extracted, where $\hat{\omega}$ is the intrinsic frequency and $N$ is the Brunt-Väisälä frequency.

Figure 3 shows the power spectral densities (PSDs) of $w_{\mathrm{GW}}$ at $17 \mathrm{~km}$ with respect to horizontal wavenumber, where $w_{\mathrm{GW}}$ denotes the wave perturbations of $w$. The PSDs are obtained by performing the one-dimensional fast Fourier transform in the zonal or meridional directions over the wave analysis domains, then averaged over time through the mature phase. For the mei-yu front, the PSDs with respect to zonal wavenumber $k$ exhibit clear meridional dependence (Figure $3 \mathrm{a})$. Along the quasi-zonal strong frontal updraft (i.e., $y=0 \mathrm{~km}$ ), the dominant zonal wavenumbers are $0.004-0.012 \mathrm{~km}^{-1}$ (i.e., wavelengths are $83-250 \mathrm{~km}$ ). Away from the updraft, the PSDs generally weaken, especially for larger wavenumbers (smaller wavelengths). In contrast, the distribution of PSDs with respect to meridional wavenumber $l$ is nearly uniform along the $x$ direction (Figure 3c). The dominant meridional wavenumbers of the waves are always smaller than $0.01 \mathrm{~km}^{-1}$ (i.e., wavelengths are larger than $100 \mathrm{~km}$ ) at different zonal positions. The waves in the TC exhibit much greater power than those in the mei-yu front (Figure 3b,d). The distribution of PSDs with respect to zonal wavenumber is almost symmetrical, about $y=0 \mathrm{~km}$, and the distribution with respect to meridional wavenumber is almost symmetrical about $x=0 \mathrm{~km}$. Away from the TC center, the wave energy at various scales weakens.
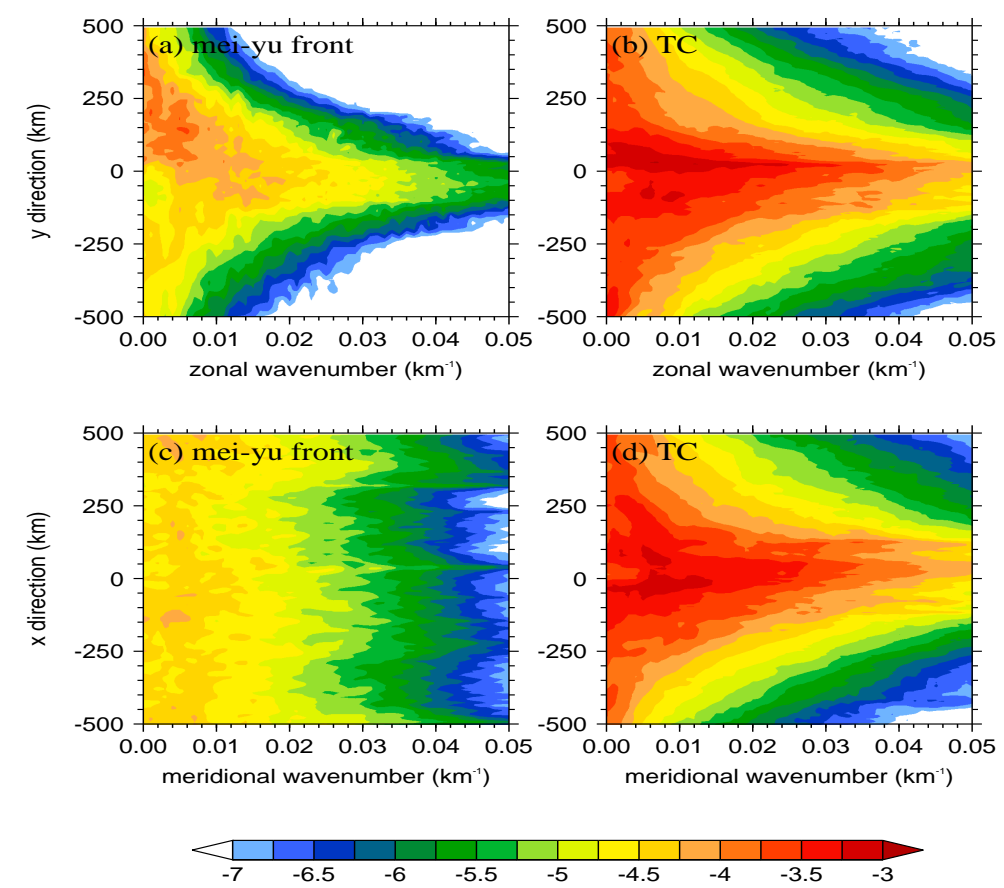

Figure 3. Base-10 logarithm of PSDs of $w_{\mathrm{GW}}\left(\right.$ shaded; $\left.\mathrm{m}^{2} \mathrm{~s}^{-2}\right)$ as a function of $(\mathbf{a}, \mathbf{b})$ zonal wavenumber and $y$ direction, and $(\mathbf{c}, \mathbf{d})$ meridional wavenumber and $x$ direction at $z=17 \mathrm{~km}$, for $(\mathbf{a}, \mathbf{c})$ the mei-yu front and $(\mathbf{b}, \mathbf{d})$ the TC.

By performing the $2 \mathrm{D}$ fast Fourier transform at the horizontal surface, we can get the $2 \mathrm{D} w_{\mathrm{GW}}$ spectra at $17 \mathrm{~km}$ with respect to the zonal and meridional wavenumber (Figure $4 \mathrm{a}, \mathrm{b}$ ). The distribution 
of PSDs in the mei-yu front shows directional selectivity, with notably deficient power found along $0^{\circ}$. By contrast, the distribution of relatively strong power tends to be closer to directions around $90^{\circ}$ and $270^{\circ}$ (Figure 4a). This suggests that the cross-frontal meridional-propagating waves dominate gravity waves generated in the front. The waves in the TC have richer information in the wavenumber space, and the PSDs exhibit a standard concentric-circle distribution around $(k, l)=(0,0) \mathrm{km}^{-1}$ (Figure $4 \mathrm{~b}$ ). This means that the strong convection in the TC can initiate gravity waves at various horizontal scales, which propagate equally in various horizontal directions.
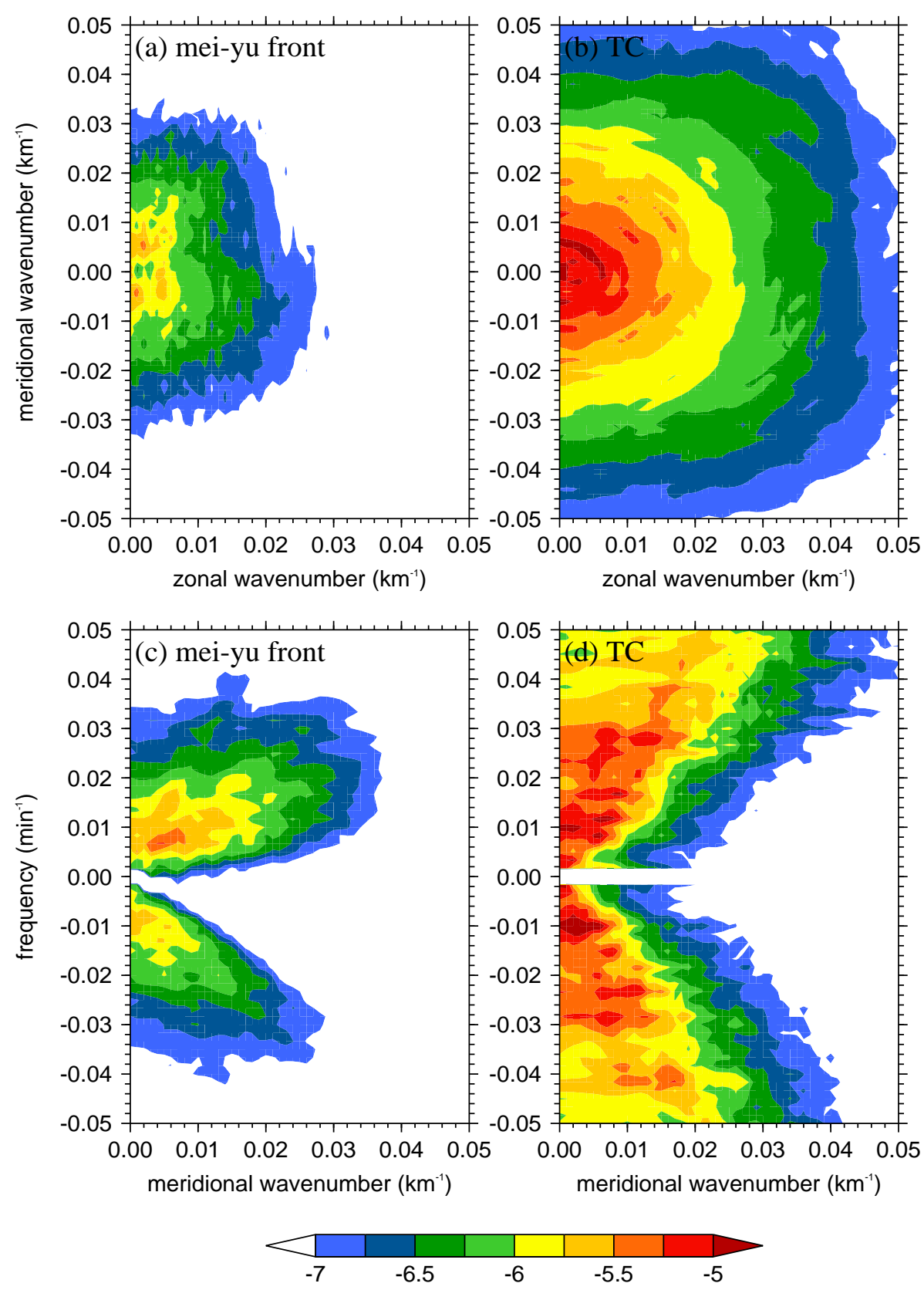

Figure 4. Base-10 logarithm of PSDs of $w_{\mathrm{GW}}$ (shaded; $\mathrm{m}^{2} \mathrm{~s}^{-2}$ ) as a function of $(\mathbf{a}, \mathbf{b})$ zonal and meridional wavenumber, and (c,d) meridional wavenumber and frequency at $z=17 \mathrm{~km}$, for $(\mathbf{a}, \mathbf{c})$ the mei-yu front and $(\mathbf{b}, \mathbf{d})$ the TC.

As highly organized convective systems, the mei-yu front and TC both consist of numerous convection clusters that continuously radiate gravity waves. They are, therefore, strong gravity wave radiators. However, the convection clusters are distinctly organized; the mei-yu front is a quasi-2D 
linear system, whereas the TC is a vortex-like system. Consequently, presented in Figures 3 and $4 a, b$, the difference in system structure gives different characteristics to the sources of gravity waves. The mei-yu front appears as a line (or narrow-band) source, the waves are radiated from the line, such that the propagation of gravity waves show obvious anisotropic, and the dominant waves propagate outwards perpendicular to the line. The front in this study is aligned in the zonal direction, thus the meridional-propagating waves dominate, showing a certain zonal homogeneity. The TC, in contrast, appears as a point (or circle) source, and the waves are radiated outwards from the point in all azimuthal directions, such that their propagation is more isotropic.

The PSDs of $w_{\mathrm{GW}}$ with respect to meridional wavenumber and frequency $\omega$ are shown in Figure $4 \mathrm{c}, \mathrm{d}$. The spectra are calculated over $y-t$ surfaces, and then averaged along the zonal direction. Note that the positive frequency implies northward propagation and negative frequency implies southward propagation. For the waves in the mei-yu front (Figure 4c), the northward-propagating components show greater power than the southward-propagating components. The former have dominant meridional wavenumbers of $0.003-0.008 \mathrm{~km}^{-1}$ (i.e., wavelengths of $125-333 \mathrm{~km}$ ) and frequencies of $0.005-0.01 \mathrm{~min}^{-1}$ (i.e., periods of 100-200 $\mathrm{min}$ ), whereas the latter have dominant meridional wavenumbers smaller than $0.004 \mathrm{~km}^{-1}$ (i.e., wavelengths larger than $250 \mathrm{~km}$ ) and frequencies of $0.007-0.012 \mathrm{~min}^{-1}$ (i.e., periods of $83-143 \mathrm{~min}$ ). The difference between waves propagating northwards and southwards is derived mainly from the background northerly wind in the lower stratosphere, which filters and modifies the wave spectra to some extent [34].

For the waves in the TC (Figure 4d), the PSDs are always symmetrical, about $\omega=0$, indicating that the wave components propagating in various directions share similar property. Differing from those in the mei-yu front, the PSDs in the TC do not show local spectral peaks at certain wavenumbers and frequencies, but have continual large values for wavenumbers smaller than $0.016 \mathrm{~km}^{-1}$ (i.e., wavelengths larger than $62.5 \mathrm{~km}$ ) and frequencies of $0.0017-0.03 \mathrm{~min}^{-1}$ (i.e., periods of 33-600 $\mathrm{min}$ ).

The meridional phase speed $\left(C_{p y}\right)$ spectra of $w_{\mathrm{GW}}$ can be further obtained from the corresponding wavenumber-frequency spectra (Figure $5 a, b)$. As expected, the spectra of waves in the mei-yu front exhibit strong zonal homogeneity (Figure 5a). Under the effect of the background northerly wind, the power of the northward-propagating waves is generally stronger than that of the southward-propagating waves. The dominant phase speeds are $5<C_{p y}<25 \mathrm{~m} \mathrm{~s}^{-1}$ for the former and $-30<C_{p y}<-15 \mathrm{~m} \mathrm{~s}^{-1}$ for the latter. The phase speed of the waves is more broadly distributed in the TC than in the mei-yu front, with the dominant phase speeds being 10-55 $\mathrm{m} \mathrm{s}^{-1}$ (Figure 5b).

To examine the wave components propagating in all directions, we provide the distribution of $w_{\mathrm{GW}}$ spectra at various magnitudes and propagation directions of the horizontal phase speed in Figure $5 c, d$, which are calculated using the similar procedures as Wei et al. [15] (Equations (A16)-(A18)). In the mei-yu front, the PSDs exist mainly in the region with phase speeds slower than $\sim 30 \mathrm{~m} \mathrm{~s}^{-1}$ (Figure 5c). On this basis, the waves show greater power in the two northward quadrants than in the two southward quadrants. For the northward-propagating components, the waves at angles of $\sim 45-135^{\circ}$, with phase speeds slower than $\sim 15 \mathrm{~m} \mathrm{~s}^{-1}$ dominate. For the southward-propagating components, the waves around an angle of $315^{\circ}$ with phase speeds of $15-20 \mathrm{~m} \mathrm{~s}^{-1}$ dominate. Moreover, note that a notable deficiency of power exists between $\sim 225$ and $\sim 315^{\circ}$ in the two southward quadrants, with phase speeds slower than $\sim 15 \mathrm{~m} \mathrm{~s}^{-1}$. In the TC, the waves show a quasi-isotropic distribution, with considerable power in almost all horizontal directions for phase speeds slower than $\sim 40 \mathrm{~m} \mathrm{~s}^{-1}$ (Figure $5 \mathrm{~d}$ ). This means that convection in the TC excites strong gravity-wave signals at a broad range of phase speeds in various directions. A slight deficiency of power for phase speeds slower than $\sim 15 \mathrm{~m} \mathrm{~s}^{-1}$ implies that the slowly propagating waves are relatively weak. 
(a) mei-yu front

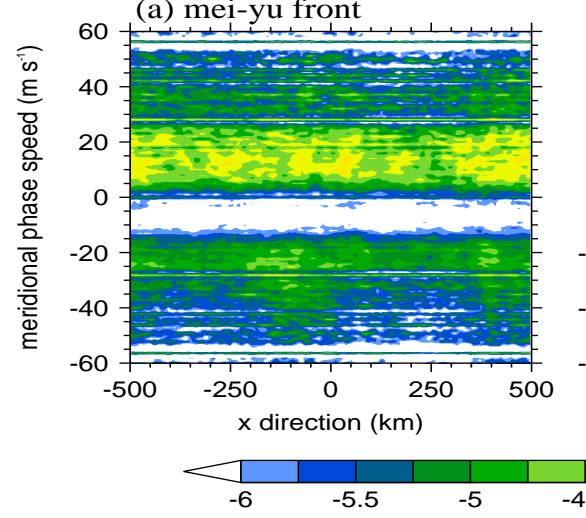

(b) TC

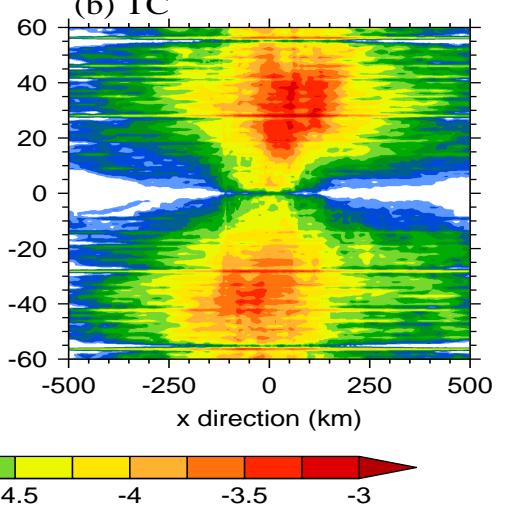

(d) $\mathrm{TC}$

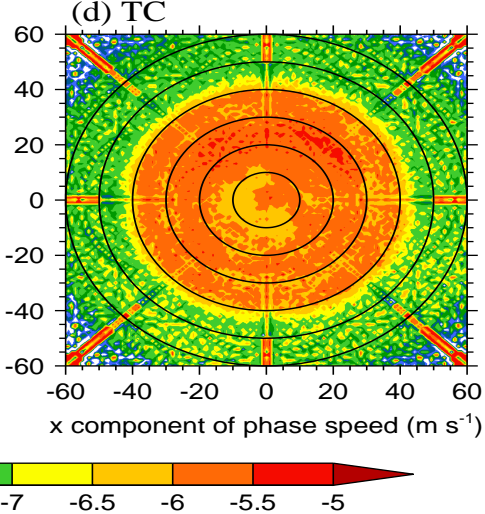

Figure 5. Base-10 logarithm of PSDs of $w_{\mathrm{GW}}$ (shaded; $\left.\mathrm{m}^{2} \mathrm{~s}^{-2}\right)$ as a function of $(\mathbf{a}, \mathbf{b}) x$ direction and meridional phase speed, and (c,d) zonal and meridional component of horizontal phase speed at $z=17 \mathrm{~km}$ for $(\mathbf{a}, \mathbf{c})$ the mei-yu front and $(\mathbf{b}, \mathbf{d})$ the TC. The black rings in the bottom panels show the magnitude of horizontal phase speed at each $10 \mathrm{~m} \mathrm{~s}^{-1}$.

\section{Conclusions}

Based on cloud-permitting simulations using the WRF model, this study compares the spectral characteristics of lower-stratospheric gravity waves in an idealized mei-yu front and TC. These two systems organize convection in different forms, which results in distinctly different presentation of the generated waves. The mei-yu front approximates to a line wave source and the generated waves propagate mainly across the front. The spectral properties of cross-frontal propagating waves remain quasi-consistent along the front. The TC resembles a point wave source, which radiates waves outwards from the storm center equally in all azimuthal directions; therefore, the wave spectra always show isotropic. The distinct difference of gravity waves in these two systems implies that the structure feature of the specific convective system should be considered in attempt to parameterize convective gravity waves in GCMs.

Filtering and modification by background northerly wind in the lower stratosphere cause the northward and southward components of gravity waves in the mei-yu front to be asymmetrical. The northward components are generally stronger than the southward components, and they show differences in spectral properties. The former (latter) have dominant meridional wavelengths of

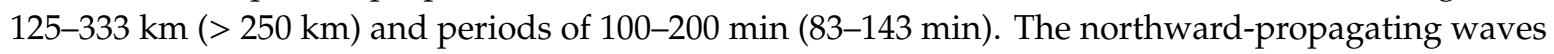
are most notable at azimuths of $\sim 45-135^{\circ}$, with dominant phase speeds slower than $\sim 15 \mathrm{~m} \mathrm{~s}^{-1}$; while the southward-propagating waves are remarkable around the azimuth of $315^{\circ}$, with dominant phase speeds of $15-20 \mathrm{~m} \mathrm{~s}^{-1}$.

Benefitting from the motionless background atmosphere from the troposphere to the lower stratosphere, the isotropic spectral properties of waves in the TC are well preserved. Compared with waves in the mei-yu front, those in the TC exhibit greater power and broader distributions in the 
spectral space. They are continually prominent at horizontal wavelengths longer than $62.5 \mathrm{~km}$, periods of 33-600 min, and phase speeds slower than $\sim 40 \mathrm{~m} \mathrm{~s}^{-1}$.

The mei-yu front and TC are both typical convective systems, but the waves which they generated exhibit considerably different spectral characteristics. The diversity of system structure combined with changeable environmental conditions make convective gravity waves in real atmosphere an intricate phenomenon. Note that we have only reserved the background wind essential for the evolution of front in our mei-yu front simulation, and even ignored it entirely in the TC simulation for simplicity. However, background flows in real atmosphere are not negligible, which will exert a significant influence on gravity waves $[14,20]$. Varying degrees of convective instability also have the potential of modifying convective gravity waves [15]. Furthermore, recent studies showed that radiative forcing, which is ignored in our TC simulation, can impact storm structure [50]. It is, therefore, reasonable to speculate that radiative forcing can also influence TC-generated waves by modifying system structure. Future work will systematically explore such issues.

Author Contributions: Conceptualization, Y.W., L.Z. and Y.Z.; formal analysis, Y.W.; methodology, Y.W. and J.P.; software, Y.W. and T.W.; validation, J.P. and T.W.; writing-original draft, Y.W.; writing-review and editing, L.Z. and J.P.

Funding: This research was funded by the Beijige Open Research Fund for Nanjing Joint Center of Atmospheric Research, grant number NJCAR2018ZD03; the National Natural Science Foundation for Young Scientists of China, grant number 41705037 and 41805092; the National Natural Science Foundation of China, grant number 41775123 and 41375063.

Conflicts of Interest: The authors declare no conflicts of interest.

\section{References}

1. $\mathrm{Xu}, \mathrm{X}$.; Shu, S.; Wang, Y. Another look on the structure of mountain waves: A spectral perspective. Atmos. Res. 2017, 191, 156-163. [CrossRef]

2. Dörnbrack, A.; Gisinger, S.; Kaifler, N.; Portele, T.C.; Bramberger, M.; Rapp, M.; Gerding, M.; Söder, J.; Žagar, N.; Jelić, D. Gravity waves excited during a minor sudden stratospheric warming. Atmos. Chem. Phys. 2018, 18, 12915-12931. [CrossRef]

3. Podglajen, A.; Plougonven, R.; Hertzog, A.; Jensen, E. Impact of gravity waves on the motion and distribution of atmospheric ice particles. Atmos. Chem. Phys. 2018, 18, 10799-10823. [CrossRef]

4. Shapiro, M.A. Turbulent mixing within tropopause folds as a mechanism for the exchange of chemical constituents between the stratosphere and troposphere. J. Atmos. Sci. 1980, 37, 994-1004. [CrossRef]

5. Lane, T.P.; Zhang, F. Coupling between gravity waves and tropical convection at mesoscales. J. Atmos. Sci. 2011, 68, 2582-2598. [CrossRef]

6. Holton, J.R.; Haynes, P.H.; McIntyre, M.E.; Douglass, A.R.; Road, R.B.; Pfister, L. Stratosphere-troposphere exchange. Rev. Geophys. 1995, 33, 403-439. [CrossRef]

7. Fritts, D.C.; Alexander, M.J. Gravity wave dynamics and effects in the middle atmosphere. Rev. Geophys. 2003, 41, 1003. [CrossRef]

8. Kim, Y.-J.; Eckermann, S.D.; Chun, H.-Y. An overview of the past, present and future of gravity-wave drag parametrization for numerical climate and weather prediction models. Atmos. Ocean 2003, 41, 65-98.

9. Alexander, M.J.; Beres, J.H.; Pfister, L. Tropical stratospheric gravity wave activity and relationships to clouds. J. Geophys. Res. 2000, 105, 22299-22309. [CrossRef]

10. Halliday, O.H.; Griffiths, S.D.; Parker, D.J.; Stirling, A.; Vosper, S. Forced gravity waves and the tropospheric response to convection. Q. J. R. Meteorol. Soc. 2018, 144, 917-933. [CrossRef]

11. Baik, J.-J.; Hwang, H.-S.; Chun, H.-Y. Transient, linear dynamics of a stably stratified shear flow with thermal forcing and a critical level. J. Atmos. Sci. 1999, 56, 483-499. [CrossRef]

12. Alexander, M.J.; Vincent, R.A. Gravity waves in the tropical lower stratosphere: A model study of seasonal and interannual variability. J. Geophys. Res. 2000, 105, 17983-17993. [CrossRef]

13. Lane, T.P.; Reeder, M.J.; Clark, T.L. Numerical modeling of gravity wave generation by deep tropical convection. J. Atmos. Sci. 2001, 58, 1249-1274. [CrossRef] 
14. Beres, J.H.; Alexander, M.J.; Holton, J.R. Effects of tropospheric wind shear on the spectrum of convectively generated gravity waves. J. Atmos. Sci. 2002, 59, 1805-1824. [CrossRef]

15. Wei, J.; Zhang, F.; Richter, J.H. An analysis of gravity wave spectral characteristics in moist baroclinic jet-front systems. J. Atmos. Sci. 2016, 73, 3133-3155. [CrossRef]

16. Pfister, L.; Chan, K.R.; Bui, T.P.; Bowen, S.; Legg, M.; Gary, B.; Kelly, K.; Proffitt, M.; Starr, W. Gravity waves generated by a tropical cyclone during the STEP tropical field program: A case study. J. Geophys. Res. 1993, 98, 8611-8638. [CrossRef]

17. Niranjan Kumar, K.; Kanaka Rao, C.H.; Sandeep, A.; Rao, T.N. SODAR observations of inertia-gravity waves in the atmospheric boundary layer during the passage of tropical cyclone. Atmos. Sci. Lett. 2014, 15, 120-126. [CrossRef]

18. Yue, J.; Miller, S.D.; Hoffman, L.; Straka, W.C., III. Stratospheric and mesospheric concentric gravity waves over tropical cyclone Mahasen: Joint AIRS and VIIRS satellite observations. J. Atmos. Sol. Terr. Phys. 2014, 119, 83-90. [CrossRef]

19. Nolan, D.S.; Zhang, J.A. Spiral gravity waves radiating from tropical cyclones. Geophys. Res. Lett. 2017, 44, 3924-3931. [CrossRef]

20. Kim, S.-Y.; Chun, H.-Y.; Wu, D.L. A study on stratospheric gravity waves generated by Typhoon Ewiniar: Numerical simulations and observations. J. Geophys. Res. 2009, 114, D22104. [CrossRef]

21. Kuester, M.A.; Alexander, M.J.; Ray, E.A. A model study of gravity waves over Hurricane Humberto (2001). J. Atmos. Sci. 2008, 65, 3231-3246. [CrossRef]

22. Chen, D.; Chen, Z.Y.; Lü, D.R. Simulation of the stratospheric gravity waves generated by the Typhoon Matsa in 2005. Sci. China Earth Sci. 2012, 55, 602-610. [CrossRef]

23. Wu, J.F.; Xue, X.H.; Liu, H.L.; Dou, X.K.; Chen, T.D. Assessment of the simulation of gravity waves generation by a tropical cyclone in the high-resolution WACCM and the WRF. J. Adv. Model Earth Syst. 2018, 10, 2214-2227. [CrossRef]

24. Wang, Y.; Zhang, L.; Zhang, Y.; Guan, J. Effects of tropospheric vertical wind shear on gravity waves generated by tropical cyclones. Geophys. Res. Lett. 2019, 46, 4523-4530. [CrossRef]

25. Sun, S. Activities of inertia-gravitational waves in bai-u front and their interaction with background field. Chin. J. Atmos. Sci. 1990, 14, 163-172. (In Chinese)

26. Xu, X.; Sun, Z. Dynamic study of influence of inertial gravity waves induced by unbalanced flow on meiyu front heavy rain. Acta Meteorol. Sin. 2004, 18, 467-478.

27. $\mathrm{Hu}, \mathrm{B}$. Evolution and propagation of MCSs over meiyu fronts and inertia gravitational wave CISK related to "low level moisture frontal zone". Chin. J. Atmos. Sci. 2005, 29, 845-853. (In Chinese)

28. Xu, X.; Xue, M.; Wang, Y.; Huang, H. Mechanisms of secondary convection within a Mei-Yu frontal mesoscale convective system in eastern China. J. Geophys. Res. Atmos. 2017, 122, 47-64. [CrossRef]

29. Luo, X.; Fei, J.; Huang, X.; Ding, J.; Ma, Z. Relative roles of dry intrusion, latent heat and instabilities in the Mei-yu rainband life cycle: A case study. Atmos. Res. 2018, 214, 10-20. [CrossRef]

30. Zhang, Y.; Zhang, F.; Davis, C.A.; Sun, J. Diurnal evolution and structure of long-lived mesoscale convective vortices along the Mei-Yu front over the East China Plains. J. Atmos. Sci. 2018, 75, 1005-1025. [CrossRef]

31. Ding, Y. Summer monsoon rainfalls in China. J. Meteorol. Soc. Jpn. 1992, 70, 373-396. [CrossRef]

32. Ding, Y.; Chan, J.C.L. The East Asian summer monsoon: An overview. Meteorol. Atmos. Phys. 2005, 89, 117-142.

33. Peng, J.; Zhang, L.; Luo, Y.; Zhang, Y. Mesoscale energy spectra of the mei-yu front system. Part I: Kinetic energy spectra. J. Atmos. Sci. 2014, 71, 37-55. [CrossRef]

34. Wang, Y.; Zhang, L.; Peng, J.; Guan, J. Mesoscale gravity waves in the mei-yu front system. J. Atmos. Sci. 2018, 75, 587-609. [CrossRef]

35. Alexander, M.J.; Geller, M.; McLandress, C.; Polavarapu, S.; Preusse, P.; Sassi, F.; Sato, K.; Eckermann, S.; Ern, M.; Hertzog, A.; et al. Recent developments in gravity-wave effects in climate models and the global distribution of gravity-wave momentum flux from observations and models. Q. J. R. Meteorol. Soc. 2010, 136, 1103-1124. [CrossRef]

36. Chun, H.-Y.; Choi, H.-J.; Song, I.-S. Effects of nonlinearity on convectively forced internal gravity waves: Application to a gravity wave drag parameterization. J. Atmos. Sci. 2008, 65, 557-575. [CrossRef]

37. Choi, H.-J.; Chun, H.-Y. Momentum flux spectrum of convective gravity waves. Part I: An update of a parameterization using mesoscale simulations. J. Atmos. Sci. 2011, 68, 739-759. [CrossRef] 
38. Lott, F.; Guez, L. A stochastic parameterization of the gravity waves due to convection and its impact on the equatorial stratosphere. J. Geophys. Res. Atmos. 2013, 118, 8897-8909. [CrossRef]

39. Bushell, A.C.; Butchart, N.; Derbyshire, S.H.; Jackson, D.R.; Shutts, G.J.; Vosper, S.B.; Webster, S. Parameterized gravity wave momentum fluxes from sources related to convection and large-scale precipitation processes in a global atmosphere model. J. Atmos. Sci. 2015, 72, 4349-4371. [CrossRef]

40. Serva, F.; Cagnazzo, C.; Riccio, A.; Manzini, E. Impact of a stochastic nonorographic gravity wave parameterization on the stratospheric dynamics of a general circulation model. J. Adv. Model. Earth Syst. 2018, 10, 2147-2162. [CrossRef]

41. De la Cámara, A.; Lott, F.; Abalos, M. Climatology of the middle atmosphere in LMDz: Impact of source-related parameterizations of gravity wave drag. J. Adv. Model. Earth Syst. 2016, 8, 1507-1525. [CrossRef]

42. Skamarock, W.C.; Klemp, J.B.; Dudhia, J.; Gill, D.O.; Barker, D.M.; Wang, W.; Powers, J.G. A Description of the Advanced Research WRF Version 3. NCAR Tech. Note NCAR/TN-4751STR. 2008, p. 13. Available online: http://citeseerx.ist.psu.edu/viewdoc/summary?doi=10.1.1.484.3656 (accessed on 16 July 2019).

43. Morrison, H.; Thompson, G.; Tatarskii, V. Impact of cloud microphysics on the development of trailing stratiform precipitation in a simulated squall line: Comparison of one- and two-moment schemes. Mon. Weather Rev. 2009, 137, 991-1007. [CrossRef]

44. Jordan, C.L. Mean soundings for the West Indies area. J. Meteorol. 1958, 15, 91-97. [CrossRef]

45. Hong, S.-Y.; Noh, Y.; Dudhia, J. A new vertical diffusion package with an explicit treatment of entrainment processes. Mon. Weather Rev. 2006, 134, 2318-2341. [CrossRef]

46. Jimy Dudhia, N.C.A.R. Prediction of Atlantic tropical cyclones with the Advanced Hurricane WRF (AHW) model. In Proceedings of the 28th Conference on Hurricanes and Tropical Meteorology, Orlando, FL, USA, 28 April-2 May 2008.

47. Hong, S.-Y.; Lim, J.-O.J. The WRF single-moment 6-class microphysics scheme (WSM6). J. Korean Meteorol. Soc. 2006, 42, 129-151.

48. Klemp, J.B.; Dudhia, J.; Hassiotis, A.D. An upper gravity-wave absorbing layer for NWP applications. Mon. Weather Rev. 2008, 136, 3987-4004. [CrossRef]

49. Park, S.-H.; Klemp, J.B.; Skamarock, W.C. A comparison of mesh refinement in the global MPAS-A and WRF models using an idealized normal-mode baroclinic wave simulation. Mon. Weather Rev. 2014, 142, 3614-3634. [CrossRef]

50. Bu, Y.; Fovell, R.; Corbosiero, K.L. Influence of cloud-radiative forcing on tropical cyclone structure. J. Atmos. Sci. 2014, 71, 1644-1662. [CrossRef] 